\title{
Toxicidade aguda e avaliação anatomopatológica em camundongos tratados com extrato da Qualea grandiflora Mart
}

\author{
Acute toxicity and anatomopathological assessment in mice \\ treated with Qualea grandiflora Mart extract \\ Toxicidad aguda y evaluación anatomopatológica en ratones de laboratorio
tratados con extracto de Qualea grandiflora Mart
}

\author{
Patrícia da Silva MANZANO ${ }^{1}$ \\ Camila Vieira de OLIVEIRA ${ }^{1}$ \\ Angela Márcia Selhorst e Silva BESERRA ${ }^{2}$ \\ Ivana Maria Povoa VIOLANTE ${ }^{2}$ \\ Rogério Alexandre dos SANTOS ${ }^{2}$ \\ Talisson Werik ALMEIDA ${ }^{3}$ \\ Rafaelle Aparecida Verão Quevedo Gomes RAUSCH ${ }^{2}$ \\ Evanice Menezes Marçal VIEIRA ${ }^{2}$ \\ ${ }^{1}$ Aluna de Graduação. Faculdade de Farmácia da Universidade de Cuiabá, UNIC/MT, Brasil \\ ${ }^{2}$ UNIC - Universidade de Cuiabá/MT, Brasil \\ ${ }^{3}$ Aluno de graduação da Faculdade de Odontologia da Universidade de Cuiabá, UNIC/MT, Brasil
}

\section{Resumo}

A utilização de plantas medicinais é umas das práticas curativas mais antigas utilizadas pela humanidade. A espécie vegetal Qualea grandiflora Mart é utilizada popularmente para tratamento de asma, úlcera e processos inflamatórios. O objetivo deste trabalho foi avaliar a toxicidade aguda do extrato aquoso de folhas de Qualea grandiflora Mart pelo teste Hipocrático em camundongos albinos Swiss Webster. Foram utilizados 48 animais, divididos em grupos, sendo 6 grupos tratados com o extrato hidroetanólico de Qualea grandiflora (HEQGM) por via oral (v.o) nas doses de 25, 50, 100, 250, 500 e $1000 \mathrm{mg} / \mathrm{kg}$ e 6 grupos tratados com o EHEQGM por via intraperitoneal (i.p) nas mesmas doses. Um animal controle foi utilizado para cada dose recebendo veículo (água destilada e DMSO, 10 $\mathrm{ml} / \mathrm{kg}$ ). Os animais foram observados individualmente em gaiolas apropriadas (campo aberto) nos tempos zero, 15 e $30 \mathrm{~min}, 1,2,4 \mathrm{e} 8 \mathrm{~h}$ durante o período de 14 dias. Foram observadas mudanças comportamentais em ambos os grupos e houve óbito nos grupos i.p 500 e $1000 \mathrm{mg} / \mathrm{kg}$. Porém, no exame histopatológico dos órgãos destes animais não se observou alterações significantes. Alguns efeitos indesejáveis observados neste estudo por meio dos parâmetros avaliados demonstram que a utilização da planta nas doses mais elevadas deve ser evitada.

Descritores: Toxicidade Aguda; Plantas Medicinais; Camundongos.

\begin{abstract}
The use of medicinal plants is one of the most ancient practices of humanity. The Qualea grandiflora Mart species is popularly used as a medical treatment for asthma, ulcer and inflammatory processes. The porpouse of this work is evaluate the acute toxicity of hydroethanolic Qualea grandiflora Mart leaf extract in Swiss Webster albino mice, by Hippocratic test. The amount of 48 mice were tested, divided into groups, of which 6 groups have been treated using hydro-ethanolic Qualea grandiflora Mart extract (EHEQGM), in 25, 50, $100,250,500$ and $1000 \mathrm{mg} / \mathrm{kg}$ doses, orally administered and 6 groups have been treated usind EHEQGM intraperitoneal injection, in the same doses. An animal has been used for each dose, receiving dissolvent liquid (distilled water and DMSO, $10 \mathrm{ml} / \mathrm{kg}$ ). The animals were watched individually, into appropriate cages (open field), instantly, after 15 and 30 minutes and after 1, 2, 4 and 8 hours. They were also watched once per day, during 14 days. Some behavioral changes were noted in both groups and there were deaths in i.p $500 / 1000 \mathrm{mg} / \mathrm{kg}$ groups, but the results of the histopathological examination did not present significant changes in these animals organs. Some noted undesirable effects during this study by assessed parameters show that the use of Qualea grandiflora Mart in high doses should be avoided.
\end{abstract}

Descriptors: Acute Toxicity; Plants, Medicinal; Mice.

\section{Resumen}

La utilización de plantas medicinales es una de las prácticas curativas más antiguas utilizadas por la humanidad. La especie vegetal Qualea grandiflora Mart es usada popularmente para tratamiento del asma, úlcera y procesos inflamatorios. El objetivo de este trabajo fue evaluar la toxicidad aguda del extracto acuoso de hojas de Qualea grandiflora Mart por la prueba de Hipócrates en ratones albinos Swiss Webster. Fueron utilizados 48 animales, divididos en grupos, siendo 6 grupos tratados con el extracto hidroetanólico de Qualea grandiflora (HEQGM) por via oral (v.o) en dosis de 25, 50, 100, 250, 500 e $1000 \mathrm{mg} / \mathrm{kg}$ y 6 grupos tratados con el EHEQGM por via intraperitoneal (i.p) en las mismas dosis. Un animal control fue utilizado para cada dosis recibiendo vehículo (agua destilada y DMSO, $10 \mathrm{ml} / \mathrm{kg}$ ). Los animales fueron observados individualmente en jaulas apropiadas (campo abierto) en tiempos cero, 15 y 30 minutos; 1,2 , 4 y 8 horas, y una vez, a cada día, por 14 dias. Fueron observados cambios comportamentales en ambos grupos y hubo muerte en los grupos i.p 500/1000 mg/kg, sin embargo en el examen histopatológico en los órganos de estos animales no se obervó alteraciones significantes. Algunos efectos indeseables observados en este estudio por medio de los parámetros evaluados demuestran que la utilización de la planta en las dosis más elevadas debe ser hecha de manera cautelosa.

Descriptores: Toxicidad Aguda; Plantas Medicinales; Ratones. 


\section{INTRODUÇÃO}

O uso de plantas medicinais propõe uma intervenção de cura e prevenção de doenças. É considerada uma das formas clássicas de terapia alternativa na população, onde esse conhecimento designa, em muitos casos, o único recurso terapêutico de muitas comunidades e grupos étnicos. Plantas medicinais são comercializadas em feiras livres e mercados populares e, muitas vezes, também são encontradas em quintais residenciais ${ }^{1}$.

Assim sendo, as plantas medicinais desempenham papel importante na medicina moderna, fornecendo fármacos importantes no qual seria dificilmente obtido por via sintética. Os compostos naturais podem ser modificados para diminuição dos efeitos tóxicos e aumento da atividade e servem como protótipo para obtenção de novos fármacos ${ }^{2}$.

A prática curativa utilizando plantas medicinais indicou que algumas espécies podem apresentar substâncias potencialmente agressivas, devendo ser utilizadas com cuidado levando em conta sua toxicidade. Como exemplos de efeitos tóxicos, as reações hepatotóxicas causadas pelas substancias apiol, safrol, lignanas e alcalóides e as reações renais causadas por espécies ricas em terpenos. Sabe-se também que diversas substancias isoladas de vegetais que são consideradas medicinais possuem atividade citotóxica ou genotóxicas estando relacionadas com a incidência de tumores ${ }^{3}$ (Junior et al., 2005).

Qualea grandiflora Mart (QGF) é uma árvore típica do Cerrado, conhecida popularmente como pauterra, pau-terra-do-campo, pau-terra-do-cerrado, pauterra-da-folha-larga, ariava, entre outros ${ }^{4}$. A infusão dos frutos é usada no tratamento de asma e a infusão das cascas, para limpeza externa de úlceras e feridas e, também, contra inflamações ${ }^{5}$.

Segundo estudo de Ayres ${ }^{6}$, a Qualea grandifora Mart apresenta atividade antimicrobiana, sendo de grande importância no combate de patógenos relacionado com a ocorrência de endocardites, bacteremias, sepse, bem como outras graves infecções envolvidas com dispositivos médicos. $\mathrm{O}$ extrato bruto das folhas possui ação depressora do sistema nervoso central, efeito analgésico e um potencial anticonvulsivo ${ }^{7}$.

O efeito tóxico desta planta foi estudado por Gaspi et al. ${ }^{7}$ em diferentes doses do extrato, sendo que na concentração de $100 \mathrm{mg} / \mathrm{kg}$ não obteve nenhum sintoma anormal, nas de 300, 500,1000 e $1500 \mathrm{mg} / \mathrm{kg}$ os animais já obtiveram sintomas anormais como cianose, pilo-ereção, contorções, ptose palpebral, tremores, convulsões e óbitos.

Apesar das plantas medicinais apresentarem efeitos benéficos revelados nos estudos, sempre se faz necessário buscar também sua segurança de uso, ou seja, conhecer a toxicidade presente nas espécies vegetais. Sabe-se que uma das formas de buscar este tipo de informação é através de experimentos de toxicidade em animais.

Diante do exposto, o propósito deste trabalho foi investigar o efeito toxicológico da Qualea grandiflora Mart por meio do teste hipocrático e análise anatomopatológica dos órgãos de camundongos albinos Swiss Webster tratados com seu extrato hidroetanólico.

\section{MATERIAL E MÉTODO}

\section{- COLETA DO MATERIAL BOTÂNICO}

As partes da planta Qualea grandiflora Mart foram coletadas no Cerrado da Região Centro-Oeste, armazenadas em recipientes apropriados, e transportadas para o Laboratório de Pesquisa de Produtos Naturais da Universidade de Cuiabá para e obtenção do extrato hidroetanólico. O material coletado foi herborizado pelo método convencional ${ }^{8}$. A identificação foi realizada através do uso de chaves específicas para identificação de família, gênero e espécie.

○ OBTENÇÃO DO EXTRATO HIDROETANÓLICO DA Qualea grandiflora Mart (EHEQGM)

O material vegetal coletado foi limpo, seco à temperatura ambiente e triturado em moinho elétrico com tamis $\mathrm{n}^{\mathrm{o}} 50$. O pó obtido foi macerado com etanol $(1: 5, \mathrm{p} / \mathrm{v})$ por 7 dias, à temperatura ambiente, filtrado, concentrado em rotaevaporador, sob pressão reduzida e temperatura de $40{ }^{\circ} \mathrm{C}$. O solvente residual foi evaporado em estufa a $40^{\circ} \mathrm{C}$, e o extrato, assim obtido, liofilizado e envasado em frasco âmbar e mantido em geladeira a $4 \pm 1^{\circ} \mathrm{C}$. No momento de uso, o EHEQGM foi dissolvido em solvente apropriado para a concentração desejada.

\section{- ANIMAIS}

Foram utilizados camundongos Mus musculus, variedade Swiss Webster, machos adultos, pesando entre (35-52 provenientes do Biotério do Hospital Veterinário da Universidade de Cuiabá-UNIC/MT. Os animais foram mantidos em caixas de prolipropileno, à temperatura variando entre $22 \pm 1^{\circ} \mathrm{C}$, sob ciclo de $12 \mathrm{~h}$ claro/escuro, com acesso a ração Purina ${ }^{\circledR}$ e água ad libitum. Foram utilizados 3 animais por grupo e 1 animal controle por grupo. Esta pesquisa seguiu os Princípios Éticos na Experimentação Animal e teve aprovação do Comitê de Ética da Universidade de Cuiabá-UNIC/MT, protocolo no 2011-044.

\section{- ENSAIO TOXICOLÓGICO}

Os animais foram tratados por via oral (v.o) com EHEQGM nas doses de 25, 50, 100, 250, 500 e 1000 e por via intraperitoneal (i.p) nas doses de 25, $50,100,250,500$ e $1000 \mathrm{mg} / \mathrm{kg}$. Um animal controle foi utilizado para cada dose recebendo Veículo (água destilada mais DMSO, $10 \mathrm{ml} / \mathrm{kg}$ (v.o) ou salina mais DMSO, 10 ml/kg (i.p). Após a administração do 
EHEQGM ou Veículo, todos os animais foram observados individualmente em gaiolas apropriadas (campo aberto) nos tempos zero, 15 e 30 min; 1, 2, 4 e $8 \mathrm{~h}$ e, uma vez, a cada dia, por 14 dias. Os resultados das observações comportamentais gerais foram anotadas em tabela adaptada dos trabalhos de Malone $^{8}$. O peso corporal ( $\mathrm{g}$ ) de cada animal foi anotado no $1^{\circ}$ dia e no $14^{\circ}$ dia para determinação do ganho de peso $(\mathrm{g})$. No final do período $\left(15^{\circ}\right.$ dia $)$ os animais foram eutanasiados e os órgãos (coração, pulmão, fígado, baço e rins) retirados, avaliados macroscopicamente e fixados em formol $10 \%$.

- PROCESSAMENTO DO ESPÉCIME PARA ANÁLISE ANATOMOPATOLÓGICO

Os órgãos vitais (coração, pulmão, fígado, baço e rins) dos animais submetidos ao teste hipocrático foram processados histologicamente para análise microscópica e identificação das alterações teciduais existentes. Este processamento foi iniciado após fixação do espécime em formol a $10 \%$ e clivagem. Após clivagem, foram realizados os processamentos histológicos de rotina, utilizando álcool e xilol em escala crescente de concentrações e posteriormente os espécimes foram incluídos em parafina. Após a inclusão os órgãos foram cortados e corados pela técnica de coloração de rotina HE (Hematoxilina/Eosina). A avaliação foi realizada através de microscopia óptica em diferentes aumentos por dois observadores.

\section{- ANÁLISE ESTATÍSTICA}

Os valores foram expressos como média \pm erro padrão da média (E.P.M.). Aos dados obtidos aplicaram-se os testes de análise de variância (ANOVA one-way) para comparações de médias seguidas por Student-Newman-Keuls teste ou pósteste de Tukey. Para comparação das medianas, um teste Kruskal-Wallis foi realizado, seguido pelo teste de Dunn. Os valores foram considerados significativos quando $\mathrm{p}<0.05$.

\section{RESULTADOS}

\section{○ TESTE HIPOCRÁTICO}

Durante a administração do (EHEQGM) nos animais por meio das vias oral e intraperitoneal em diferentes doses, observou-se que na administração via oral nas doses de 25, 50, 100, 250 e $500 \mathrm{mg} / \mathrm{kg}$, não houve nenhuma alteração comportamental nos animais, enquanto que na dose de $1000 \mathrm{mg} / \mathrm{kg}$ houve alteração dermatológica representando clinicamente área desnuda na região dorsal. $\mathrm{Na}$ administração (i.p), foram observadas alterações comportamentais nas doses de 100, 250 e $500 \mathrm{mg} / \mathrm{kg}$, inclusive com registros de óbito, onde observou-se ulcerações e petéquias na dose de $100 \mathrm{mg} / \mathrm{kg}$ e redução na quantidade de fezes, interpretado como constipação na dose de $250 \mathrm{mg} / \mathrm{Kg}$. (Tabela 1 )
Tabela 1. Efeitos da administração do extrato da Qualea grandiflora Mart (EHEQGM) sobre as atividades comportamentais gerais em camundongos

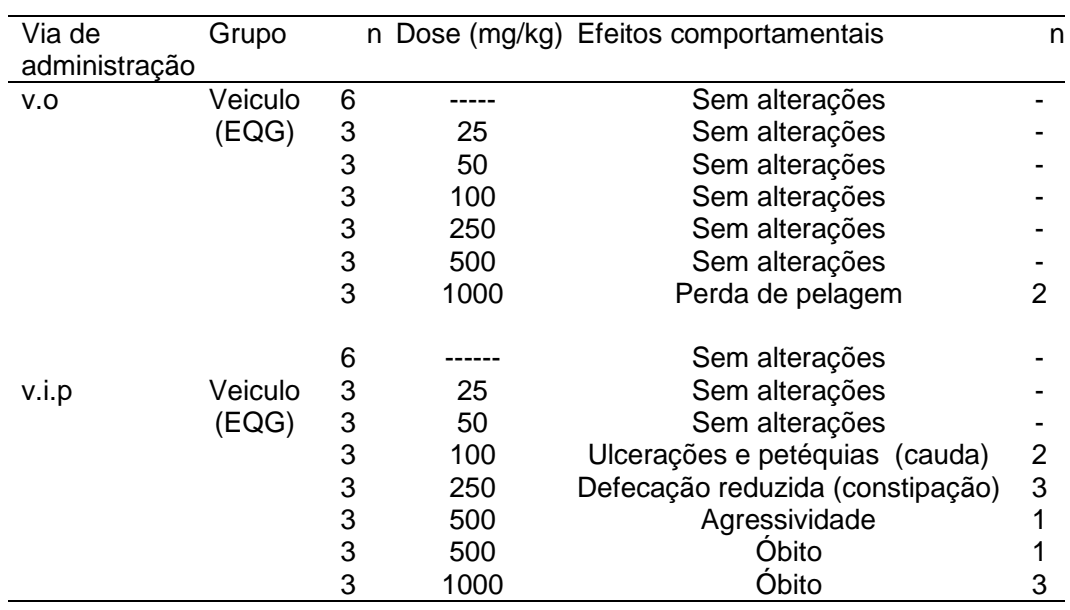

Nenhum animal apresentou cianose, piloereção, contorções, ptose palpebral, tremores, convulsões, urina vermelha ou diarreia em nenhumas das vias de administração. Houve registro de morte em todos os animais tratados com dose de $1000 \mathrm{mg} / \mathrm{kg}$. Em relação ao peso, valores referentes a aquisição e perda de peso encontram-se expressos na tabela 2.

Tabela 2. Efeitos da administração do extrato da Qualea grandiflora Mart (EHEQGM) no peso dos camundongos no período de 14 dias

\begin{tabular}{|c|c|c|c|c|c|}
\hline \multirow{2}{*}{$\begin{array}{c}\text { Via de } \\
\text { administração }\end{array}$} & \multirow[t]{2}{*}{ Grupo } & \multirow{2}{*}{$\begin{array}{l}\text { Dose } \\
\mathrm{mg} / \mathrm{kg}\end{array}$} & \multicolumn{2}{|c|}{ Peso corporal (g) } & \multirow{2}{*}{$\begin{array}{l}\text { Ganho de } \\
\text { peso }(\mathrm{g})\end{array}$} \\
\hline & & & $\begin{array}{l}1^{\circ} \text { dia } \\
\text { dia }\end{array}$ & $14^{\circ}$ & \\
\hline \multirow[t]{6}{*}{ v.o } & EHEQGM & Controle & $42 \pm 2,08$ & $45,7 \pm 2,12$ & 3,7 \\
\hline & & 25 & $44,3 \pm 1,78$ & $48,0 \pm 2,08^{*}$ & 3,7 \\
\hline & & 50 & $42,7 \pm 3,28$ & $42 \pm 2,88$ & $-0,7$ \\
\hline & & 100 & $35,7 \pm 1,76$ & $37,7 \pm 1,76$ & 2.0 \\
\hline & & 250 & $37,33 \pm 2,90$ & $39,3 \pm 2,90$ & 2,0 \\
\hline & & $\begin{array}{c}500 \\
1000\end{array}$ & $\begin{array}{l}43,0 \pm 1,73 \\
42,3 \pm 1,85\end{array}$ & $\begin{array}{l}44,0 \pm 3,05 \\
48,0 \pm 1,73^{* *}\end{array}$ & $\begin{array}{l}1,0 \\
5,7\end{array}$ \\
\hline \multirow[t]{7}{*}{ v.i.p. } & & Controle & $48,7 \pm 3,02$ & $50,8 \pm 2,41$ & 2,1 \\
\hline & EHEQGM & 25 & $45,3 \pm 1,85$ & $47,0 \pm 2,64$ & 1.7 \\
\hline & & 50 & $46,3 \pm 1,20$ & $49,0 \pm 1,73$ & 2,7 \\
\hline & & 100 & $44,0 \pm 4,58$ & $43,3 \pm 1,33$ & $-0,7$ \\
\hline & & 250 & $50,3 \pm 2,02$ & $57,0 \pm 5,29^{* *}$ & 6,7 \\
\hline & & 500 & $52,7 \pm 0,66$ & $51,0 \pm 0,58$ & 1,7 \\
\hline & & 1000 & $40,1 \pm 0,67$ & $40,1 \pm 0,67$ & 0 \\
\hline
\end{tabular}

\section{- AVAliaçÃo histopatológicA}

Pulmão: Na dose de 25, 50, 250 e $1000 \mathrm{mg} / \mathrm{kg}$ (v.o), não foi identificada nenhuma alteração no órgão examinado, porém na dose de $100 \mathrm{mg} / \mathrm{kg}$, foi observado discreto infiltrado inflamatório crônico focal. Na dose de $500 \mathrm{mg} / \mathrm{kg}$, somente o animal do grupo controle, apresentou as mesmas alterações descritas no grupo de $100 \mathrm{mg} / \mathrm{kg}$, o que enfatiza a hipótese levantada em relação a ausência de efeito desta magnitude pela planta. Em todos os grupos as células mesangiais pavimentosas se apresentaram integras e a pleura pariental e visceral se mostrou sem nenhuma alteração. Houve alteração tecidual em todas as doses (i.p), sendo que na dose de $25 \mathrm{mg} / \mathrm{kg}$, observou-se discreta hiperplasia focal e nas doses de $50 \mathrm{mg} / \mathrm{kg}, 100 \mathrm{mg} / \mathrm{kg}$ e $250 \mathrm{mg} / \mathrm{kg}$ observou-se degeneração hialina na parede de artérias localizadas.

Fígado: Nas doses de 25, 50, 100 e $250 \mathrm{mg} / \mathrm{kg}$ (v.o) não houve alteração, porém na dose de $500 \mathrm{mg} / \mathrm{kg}$, foi observado discreto infiltrado 
inflamatório crônico ao redor da veia centro lobular em apenas uma região. $\mathrm{Na}$ dose de $1000 \mathrm{mg} / \mathrm{kg}$ na extremidade do órgão observou-se hepatócitos hipercromáticos e hipertrofiados em pequena quantidade, sendo que alguns apresentaram hepatocariólise. Nas demais estruturas, como capilares sinusóides e espaço porta, nenhuma alteração foi identificada. Não houve alterações histopatológicas nos animais tratados (i.p).

$\checkmark \quad$ Rim: Nas doses 25, 100, 250 e 1000 mg/kg v.o, nenhuma alteração foi observada, porém na dose de 50 $\mathrm{mg} / \mathrm{kg}$ observou-se congestão vascular na cortical (alça de Henle) em pequena quantidade e na dose de $500 \mathrm{mg} / \mathrm{kg}$ notou-se discreta congestão vascular e discreto infiltrado inflamatório crônico entre os glomérulos. Quando o extrato foi aplicado i.p na dose de $100 \mathrm{mg} / \mathrm{kg}$ nenhuma alteração tecidual foi observada, porém nas doses de 25,50 e $250 \mathrm{mg} / \mathrm{kg}$ observou-se uma pequena área focal bem delimitada de infiltrado inflamatório crônico do tipo linfocitário próximo ao túbulo coletor. Por serem alterações focais e discretas, não se observou no animal nenhuma manifestação clínica, correspondente a este achado.

Nos órgãos coração e baço, não foi detectada nenhuma alteração histopatológica de interesse para este estudo, considerando tanto as vias de administração, quanto a dose administrada.

Pelo fato dos animais não apresentarem alterações clínicas compatíveis com as poucas e discretas alterações anatomopatológicas observadas em alguns órgãos, aspectos microscópicos dos órgãos examinados são apresentados na Figura 1.

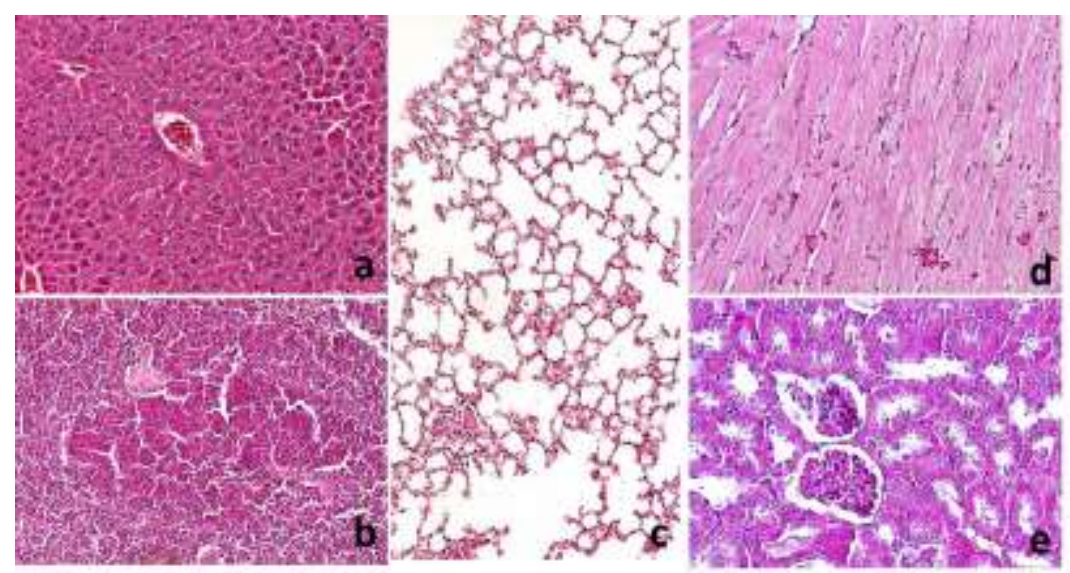

Figura 1. Coloração HE - Aumento 40x - Órgãos submetidos ao exame anatomopatológico: a) Figado; b) Baço; c) Pulmão; d) Coração; e) Rim. Não se observou alterações histopatológicas relevantes.

\section{DISCUSSÃO}

O teste hipocrático é considerado um teste preliminar de toxicidade e deve ser utilizada para seleção de doses e vias de administração ${ }^{9}$. Visando possível utilização clínica devem ser utilizadas as mesmas vias de administração que se utiliza em humanos, em que uma das vias de escolha para este estudo foi a via oral. Na literatura, é frequente a utilização de animais para este tipo de experimento, principalmente como estudo prévio visando posterior utilização em humanos ${ }^{11-13}$.

O objetivo do presente estudo foi avaliar a toxicidade aguda através do teste hipocrático e das análises anatomopatológicas em camundongos submetidos ao tratamento do extrato hidroetanólico de folhas Qualea grandiflora Mart em diferentes concentrações. Gaspi et al. ${ }^{7}$ fez a análise toxicológica da mesma espécies em concentrações de 300, 500, 1000 e $1500 \mathrm{mg} / \mathrm{kg}$.

Neste estudo, os animais foram avaliados em relação às alterações detectadas nas duas diferentes vias de administração e nas diversas doses de utilização, sendo que a constipação, perda de pelagem dentre outras, também foram registradas em estudos anteriores $^{14,15}$. Quanto à alteração de maior importância caracterizada pelo óbito, houve ocorrência nos animais submetidos às maiores doses do extrato, sendo mais significativa na dose mais elevada $(1000 \mathrm{mg} / \mathrm{kg})$ e pela via intra peritoneal, resultados também observados por Gaspi et al. ${ }^{7}$ na maior concentração de $1500 \mathrm{mg} / \mathrm{kg}$. Este autor inclusive sugeriu que uma dose de $1321 \mathrm{mg} / \mathrm{kg}$ de extrato poderia ser considerada a dose letal média. Sendo assim, quanto mais elevada a dose, mais distante deve ficar sua recomendação de uso.

Durante todo o experimento nenhum animal apresentou cianose, piloereção, contorções, ptose palpebral, tremores, convulsões, urina vermelha ou diarreia em nenhumas das vias de administração. Em trabalho publicado, utilizando a mesma planta, pode constatar ação depressora do sistema nervoso central, na dose de $500 \mathrm{mg} / \mathrm{kg}^{7}$.

Em relação ao peso dos animais durante o experimento, observou-se que os animais que receberam EHEQGM apresentaram alteração no peso durante o período de experimento, sendo mais significativo na dose mais elevada pela via oral e na dose intermediária via intraperitoneal.

Os órgãos submetidos ao exame histopatológico dos animais foram: pulmão, fígado, rim, coração e baço, baseado nos trabalhos publicados com a mesma finalidade deste estudo ${ }^{11,16-18}$. Nos órgãos avaliados não foram identificadas alterações relevantes em relação à toxicicidade da planta, como nas investigações publicadas, por exemplo: largamento dos lóbulos e erosão de mucosa bronquiolar do pulmão e focos de hepatocitólise no fígado quando submetidos ao tratamento de extrato de Jatropha gossypiifolia, congestão e infiltração leucocitária no fígado, nos rins e nos pulmões dos animais tratados com látex de Synadenium umbellatum e hepatite reacional com portite linfocitária crônica e lobular multifocal, hiperplasia kupferiana, colapsos focais da trama reticular quando submetidos com extrato de Cissus sicyoides relatada em estudos anteriores ${ }^{16-18}$. Dados semelhantes ao encontrado neste estudo foram 
relatados, mostrando a integridade dos órgãos examinados em relação ao uso da planta utilizada ${ }^{11}$, conforme demonstrado na Figura 1.

\section{CONCLUSÃO}

Os dados obtidos neste estudo de toxicidade aguda mostraram que não houve alteração indicativa de toxicidade nos animais submetidos à administração do extrato pela via oral, em todas as doses testadas, o que assegura a utilização da planta; porém pela via intra peritoneal, o registro de óbitos nas doses mais elevadas (500 e $1000 \mathrm{mg} / \mathrm{kg}$ ), torna-se inviável a utilização do extrato hidroetanólico da Qualea grandiflora Mart.

\section{AGRADECIMENTOS}

$\mathrm{O}$ presente estudo recebeu apoio financeiro da Fundação de Amparo a Pesquisa do Estado de Mato Grosso (FAPEMAT). Processo: 752090/2011.

\section{REFERÊNCIAS}

1. Maciel MAM, Pinto AC, Veigas-Junior VF. Plantas Medicinais: A necessidade de estudos Multidisciplinares. Quim Nova. 2002;25(3):429438.

2. Turolla MSR \& Nascimento ES. Informações toxicológicas de alguns fitoterápicos utilizados no Brasil. Rev Bras Farmacogn . 2006;42(2):289-306.

3. Veiga Junior VF, Pinto AC, Maciel MAM. Plantas medicinais: Cura segura? Quim Nova. 2005;28(3):519-28.

4. Corrêa MP. Dicionário de plantas úteis do Brasil e exóticas cultivadas. Ministério da Agricultura; Instituto Brasileiro de Desenvolvimento Florestal. Rio de Janeiro; 1978.

5. Sousa CMM, Silva HR, Vieira-Junior GM, Ayres MCC, Costa CLS, Araújo DS, et al. Fenóis totais e atividade antioxidante de cinco plantas medicinais. Quim Nova. 2007;30(2):351-355.

6. Ayres MCC, Escórcio SP, Costa DA, Chaves MH, Vieira-Junior GM, Cavalheiro AJ. Constituintes químicos das folhas de Qualea grandiflora: Atribuição dos dados de RMN de dois flavonóides glicosilados acilados diastereoisoméricos. Quim Nova. 2008; 31(6):1481-1484.

7. Gaspi FOG. Foglio MA, Carvalho JE, Moreno RA. Pharmacological activities investigation of crude extracts and fractions from Qualea grandiflora Mart. Journal of Ethnopharmacol. 2006;107:19-24.

8. Malone $\mathrm{MH}$. The pharmacological evaluation of natural products general and specific approaches to screening ethnopharmaceuticals. J Ethnopharmacol. 1983;8(2):127-47.

9. Joly AB. Botânica: Introdução à Taxonomia Vegetal. São Paulo: Cia. Ed. Nacional; 1977.
10. Reichert CL, Costa APR, Gazola A, Di Pieri CH, Silva ECS, Lima TCM. Fitoquímica e atividade farmacológica preliminar do extrato aquoso de Tynanthus micranthus Corr. Méllo ex K. Schum: Um exemplo da capacidade preditiva e dos custos no desenvolvimento de novos produtos farmacêuticos. Arch Vet Sci. 2014;19(1):51-60.

11. Costa JP, Lourenço NV, Menezes CC, Patrício Santos, Tomé AR, Sousa GF, et al. Avaliação da toxicidade aguda e das alterações histopatológicas em camundongos tratados com fitol. Rev Ciênc Farm Básica Apl. 2012;33(3):421-8

12. Pereira CB, Marin A, 2; Dalmora SL, Necchi RMM, Moresco RN, Manfron MP. Atividade antiinflamatória e avaliação da toxicidade do extrato hidroetanólico de Morus alba (Moraceae). Rev Ciênc Farm Básica Apl. 2013;34(1):43-6.

13. Cunha LC, Melo DFA, Pereira ME, Melo DS, Parente LL, Silva MAC, et al. Avaliação da toxicidade aguda do extrato aquoso de Apeiba tibourbou Aubl (Tiliaceae), em camundongos e ratos. Rev Ciênc Farm Básica Apl. 2013;34(3):357-62.

14. Santos JCA, Riet-Correa F, Simoes SVD, Barros CSL 2008. Patogênese, sinais clínicos e patologia das doenças causadas por plantas hepatotóxicas em ruminantes e equiinos no Brasil. Pesq Vet Bras 28(1):1-14

15. Craveiro ACS, Carvalho DMM, Nunes RS, Fakhouri R, Rodrigues AS, Teixeira-Silva F. Toxicidade aguda do extrato aquoso de folhas de Erythrina velutina em animais experimentais. Rev Bras Farmacogn.2008;18(suppl):739-43.

16. Vasconcelos THC, Modesto-Filho J, Diniz MFFM, Santos HB, Aguiar FB, Moreira PVL. Estudo toxicológico pré-clínico agudo com o extrato hidroalcoólico das folhas de Cissus sicyoides L. (Vitaceae). Rev Bras Farmacogn. 2007;17(4): 583-91.

17. Mariz SR, Araújo MST, Cerqueira GS, Araújo WC, Duarte JC, Diniz MFFM, et al. Avaliação histopatológica em ratos após tratamento agudo com o extrato etanólico de partes aéreas de Jatropha gossypiifolia L. Rev Bras Farmacogn. 2008;18(2):213-6.

18. Cunha L, Azeredo FS, Mendonça ACV, Vieira MS, Pucci LL, Valadares MC, et al. Avaliação da toxicidade aguda e subaguda, em ratos, do extrato etanólico das folhas e do látex de Synadenium umbellatum Pax. Rev Bras. Farmacogn. 2009;19(2A):403-11 
Arch Health Invest (2016) 5(1): 37-42

\section{CONFLITO DE INTERESSES}

Os autores declaram não haver conflitos de interesse.

\section{AUTOR PARA CORRESPONDÊNCIA}

Evanice Menezes Marçal Vieira

pedroferreirabmf@gmail.com

Submetido em 29/01/2016

Aceito em 04/02/2016 